\title{
Contactos con la vida material en Zamora. Siglos XII-XV
}

\author{
MARIA LUISA Bueno Domínguez \\ Universidad Autónoma de Madrid
}

\begin{abstract}
RESUMEN
El articulo trata de hacer una aproximación a la ciudad de Zamora desde tres puntos de vista. Por una parte, el paulatino ensanchamiento del espacio urbano en función de las pueblas, me he centrado en aquellas que me permitian ofrecer datos más concretos con respecto a la vida de una ciudad medieval en este caso Zamora. Acercándome a los lugares privados, las casas y a los públicos, calles y plazas por donde las personas realizaban su vida cotidiana.

En un segundo apartado se hace una valoración de los espacios públicos por excelencia y aqui me centro

fundamentalmente en describir los espacios donde la gente se abastecía de alimentación y qué tipo de mercado nos encontramos. De esta manera todas las iglesias, las plazas toman un significado

muy distinto porque adquieren vida al acercarnos a las necesidades de la ciudad. Finalmente, y en un tercer apartado, entro en la parte de la ciudad gremial, analizando los diferentes trabajos $y$ actividades que alli se dieron.
\end{abstract}

\section{PALABRAS CLAVE}

Collatio, historia urbana, urbanismo, pueblas, calles plaza, mercado.

\section{ABSTRACT}

The article tries to make an approach of the city of Zamora, from three points of view. The first one, considering the progressive expansion of the urban space in towns, I have focused my approach in those which could offer me more precise data about the life in a Medieval city, in this case, Zamora. Coming up to the private places, houses and common places, streets and squares, where people carried our their daily life.

Secondly, there is an assessment of the common places par excellence, and here I fundamentally concentrate the description of the places where people obtained food, and which type of market we find. This way, all the churches and squares adopt a very different meaning because they acquire vitality while they bring us nearer to the city necessities. Finally, and in third place, I get into the guild area of the city, analyzing the different jobs and activities that took place there.

\section{KEY WORDS}

Collatio, urban history, urbanism, towns, streets, squares, craftsmen, market. 


\section{EL PAULATINO ENSANCHAMIENTO DEL ESPACIO URBANO EN FUNCIÓN DE LAS PUEBLAS}

A lo largo de la historia de Zamora en el siglo $x$ dejé claramente establecido que uno de los elementos que definían la existencia de una ciudad era la de contar con un recinto fortificado, un episcopado y un territorio que dependiera del núcleo urbano '. Efectivamente en la documentación manejada todo esto se podia apreciar. Por un lado el recinto amurallado que determina ya de por sí u un lugar que se opone a lo que es abierto, lugar cerrado y por lo tanto diferente lo que implicaba unas formas de vida y unas necesidades sociales peculiares y distintas a las que se desarrollaban allí donde no existia tal condición. El episcopado, fundado a principios del siglo $x$, implicaba por un lado que se daba estabilidad al lugar y por otro la llegada de una población eclesiástica que llevaría a cabo una construcción de las iglesias, urbanizando asi el espacio. La importancia del territorio queda fuera de toda duda.

Fernando I llevaría a cabo una recuperación de la ciudad hacia 1060. En esa labor de restauración se aprecian los siguientes aspectos. En primer lugar un asentamiento de la población o casi mejor podríamos decir que se produce un aumento de la misma quizá en base a una serie de privilegios para los que acudiesen a poblar el lugar. Como mención importante de estos momento suele citarse a los pobladores palentinos que se agruparon en la zona septentrional de la ciudad ${ }^{2}$. Los pobladores llegados a Zamora fueron asentados en los llanos de Santa Cristina al que se le concede un fuero 1062. El segundo elemento de importancia serian las reconstrucciones, se preocupó de las iglesias de Santa María, de San Juan, de San Pedro y San Salvador, reconstrucción de la muralla en cierta manera se lleva a cabo la organización de la ciudad. Por tanto y a tenor de lo que escribo se puede decir que en este perido se dieron tres aspectos en la restauración de la ciudad. La reedificación de la muralla, la ampliación de la población, con un predominio de gentes leonesas y por otra parte y en tercer lugar se concedió un documento jurídidco, que indicaba como había que regir la ciudad.

En los años finales del siglo xI, es decir con Alfonso VI, la ciudad de Zamora, como casi todas las ciudades que comienzan su andadura en el siglo $x$, señalaría el momento de una apertura que dará pasó a un verdadero e importante núcleo urbano que se desarrolla a lo largo del siglo XII y XIII. La presencia de Raimundo de Borgoña en esta etapa de finales del siglo XI, lleva a Zamora un importante contigente que procede de Francia, gentes del norte y mozárabes son los pobladores de este momento.

Suelen señalarse tres recintos amurallados fruto de las distintas ampliaciones.

1 Véase mi estudio Zamora en el siglo x, Zamora 1983. En el citado estudio expongo los criterios que me hicieron valorar que Zamora en el siglo $x$ fue algo más que una simple fortaleza.

2 Veáse mi estudio Zamora de los siglos XI-XIII, pág. 25, Zamora 1988, Ch. Julien Bishko, esta iglesia de San Antolín sería un claro vestigio de la influencia francesa. 


\section{a) Primer recinto}

Se extendía desde la Puerta de Olivares, que hoy conocemos con el nombre de Puerta del Obispo, a Peñas de Santa Marta, Iglesia de San Pedro, donde se abría otra puerta, y seguía a San Cebrián, hoy San Cipriano, cuya torre, ejercía unas funciones de vigilancia sobre la ciudad. La muralla torcia desde San Cebrián a la Alcazaba, de aquí a San Juan, donde se abriría otra puerta que se llamaría de San Juan de Puerta Nueva. El recinto bajaba entre la Cárcaba y Zambranos, donde hacía muro con el palacio de la Reina, palacio cuya fachada daba a la conocida plaza de la "Leña", allí se abría la puerta de San Bartolomé, nombre que le vino de la presencia en ese lugar de una iglesia bajo esta advocación. Seguía por la ronda de Santa Maria, San Martín con otra puerta, y desde aquí a la puerta del Mercadillo, para avanzar hasta la puerta de Santa Coloma, terminando en la de Olivares. Este recinto tenía en principio un total de siete puertas: Olivares o del Obispo, San Pedro, San Cipriano, puerta de san Bartolomé, San Martín, Mercadillo y Santa Coloma, añadiéndose una octava al abrirse la de San Juan, puertas de suma importancia porque a través de ellas se canalizaba la vida urbana. Fundamentales la puerta de Olivares y la de Puerta Nueva daban entrada al interior de la ciudad, y se comunicaban mutuamente a través de un camino que se denominaba carral maior. La puerta de San Pedro abría directamente al carral mayor que daba la posibilidad de acceder a la rua del mercadillo. La puerta de Santa Coloma se localizaba muy cerca de la catedral. En este primer recinto se encontraban dos núcleos básicos. El Castillo y la Iglesia de San Salvador. Núcleo denso que hizo necesario que Alfonso VII en el siglo XII llevara a cabo la restauración del episcopado y la de la catedral. Hemos señalado la colación de San Salvador, que debió estar prácticamente en manos de los eclesiásticos. Al lado de ésta se encontraban las de San Pedro, San Cebrián: San Simón, donde algunos autores localizaban un núcleo de judíos. En el carral mayor se encontraba la Iglesia de la Magdalena, iglesia que como se deduce del fuero, fue una iglesia donde se reunía el concejo en ocasiones. En este núcleo se concentraba la vida ordinaria y económica diaria, de ahí la existencia de un mercadillo y de una calle que llevaba este nombre. Importante es la colación de Santa María la Nueva, quizá se pueda decir que estamos ante un núcleo de población, o colación más importante de la ciudad porque en ella habitaba una población que combatía, los milites, en definitiva de nobles no lejos se levantaría la iglesia de San Juan en las proximidades de Puerta Nueva ${ }^{3}$. Nombres significativos que suponen un acercamiento a las realidades urbanas. Un carral mayor que era una calle larga, recta que llegaba desde la iglesia del Salvador hasta el mercadillo y de este a Puerta Nueva, suponemos que entorno a ella se canalizaba la vida en el siglo XII. Mercadillo, lugar de un incipiente mercado donde se citan carnicerías o macellum y una ferrería, esto en el año 1125. La colación de San Simón, que en el siglo xill aparece con el asentamiento de algunos judíos y

A. Represa, Génesis y Evolución urbana de la Zamora medieval, en Hispania Tomo XXXII (1972), pág. 8. 
que en el siglo XIV quizá se constituye una judería, que llevaría anexo la Sinagoga y las carnicerías.

\section{b) Segundo recinto}

El segundo recinto está en conexión con el ensanche de la ciudad y la densificación de la población. En su dia A. Represa puso de manifiesto como el tipo dominante de aglomeración sería la puebla en torno a una iglesia "con cierto perfil de aldea" para los comienzos, desligada en ocasiones del conjunto de la ciudad por ser un núcleo privilegiado y contar además con magistrados autónomos. Centra la actividad repobladora en las iglesias y monasterios fundamentalmente. Este segundo recinto arrancaba de San Bartolomé, cercano al póstigo de la Reina, es decir Arco de doña Urraca, bordeando la puebla de la lana y la Iglesia de San Sebastián, llegando a la puerta de Santa Ana, donde iba la puebla de Torcaz, continuando a la de San Miguel, que enlazaba con la de San Pablo que en línea recta y por la cuesta del caño iba por Santa Eulalia y Balborraz, donde se abria una puerta que comunicaba con la fortaleza. Aquí también aparecen importantes puertas como la de San Miguel el Burgo, que cambiaría su nombre por el de Santa Clara, haciendo alusión a la construcción en ese lugar de un monasterio de las clarisas. En líneas generales este núcleo surge a partir del extremo de lo que se llamaba carral mayor, que en línea recta iba a desembocar a Puerta Nueva convergiendo con tres importantes vias: rua de San Andrés, rúa de los Francos y Balborraz. Surge también ahora en la "renova" la siguiente colación, la de Santiago el Burgo, que va a ser el ensanche moderno de la ciudad Zamora.

Un repaso por la documentación nos permite asegurar que este núcleo no estaba densamente poblado y que al no estarlo ofrecía un número importante de espacios verdes, huertos y herreñales, como puede verse, por ejemplo, en el año 1138 al situar el monasterio de San Torcuato, la documentación es muy precisa. La Iglesia de San Torcuato, lo que sería después la puebla, se situaba entre dos muros, es decir se hace mención como se puede observar a que la Iglesia se ubica entre lo que sería lo viejo y la nueva ampliación. La colación de San Antolín, situada también en el Burgo, no tenía una densa población tampoco, y más tarde el Monasterio de Moreruela se encargaría de llevar aquí la repoblación ${ }^{4}$.

El monasterio de San Esteban se situaba en el límite de tres pueblas; La del Burgo, San Torcuato y la de la Lana, que se corresponde con tres iglesias muy definitivas: Santiago del Burgo, San Torcuato y la de San Antolín ${ }^{5}$.

Aparece mencionado en el año 1186 el citado monasterio de San Esteban cuando obispo Guillermo de Zamora de illum monasterium Sancti Stephani frati

${ }^{4}$ A. Represa, Génesis y evolución urbana en la Zamora medieval, Señala como en el siglo xiII la colación de San Antolin era precaria, como lo demuestra que en el 1296 Fernando IV autorizaba al monasteriode Moreruela a realizar una repoblación, en Hispania Tomo XXXII (1972), pág. 13.

5 Véase mi estudio Zamora siglo xi... ob. cit., pág. 90. 
Garsie " 6 . Este monasterio parece haber tenido su ubicación en la actual «Iglesia de los Padres", no constituyó en ningún momento una importante colación. Entre este monasterio y el de San Torcuato hay una diferencia y es que éste tuvo una evolución importante, ya que de monasterio en el 1138 pasa a ser Iglesia y cabeza de una colación de bastante importancia, dependia del monasterio de San Martín de Castañeda. A reseñar, la diversidad de la población en esa colación.

Esta colación demostraría que, en líneas generales, las situadas en vías principales o generales alcanzaban mayor densidad que las que no tenían esta situación. Otras colaciones fueron San Pablo en la rúa de San Andrés que tenía vigencia en el siglo XIII, cercana a la muralla, otra la de Santa Eulalia del Burgo, San Salvador de la Vid, San Sebastián, San Vicente.

\section{c) Tercer recinto}

Otra de las pueblas más tempranas y de amplio desarrollo y que cubría el tercer recinto amurallado que corría próximo al río fue la puebla del Valle primer núcleo extramuros de la ciudad de Zamora a la que Raimundo de Borgoña concedió el fuero, quizá teniendo como modelo el de Santa Cristina, zona que se pobló como ya vimos en tiempo de Fernando ${ }^{7}$, esta primitiva aglomeración se refuerza en el siglo XII y pasará a ser el lugar comercial por excelencia de la ciudad de Zamora, donde los comerciantes tienen mucho protagonismo.

El núcleo del valle englobaba Santa Lucia, Santa María la Horta y Santo Tomé. Localizado en las proximidades de Balborraz es uno de los núcleos que se incrementan más fuertemente. En el año 1128 se llevó a cabo la erección del monasterio de Santo Tomé. La hermana de Alfonso VII le concedía la Iglesia de Santa María de Matilla, momento en que el monasterio era de monjes regulares. En 1135 el propio Alfonso VII cede a Santo Tomé, que ya era iglesia y no monasterio, lo que indica el progreso de esta puebla, a San Salvador, como sede de la Catedral, mientras se llevaban a cabo las obras de construcción y ampliación de la Catedral. Aunque nunca se trasladó alli. En 1139 el rey vuelve a donar a la catedral, esta vez la parte que tenía en la presa de Pinilla y dice: "et est ipsa presa in flumine dorii iuxta Cemora prope Santo Tomé ecclesiam" ${ }^{8}$, la ubicación de ésta es cercana al río Duero. El crecimiento de esta puebla lo evidencia no sólo la conversión de monasterio en Iglesia, sino la proliferación de iglesias que se producen en ella a lo largo del siglo xII: San Leonardo, próxima a una sinagoga de judíos, Santa María La Horta, que pertenecía a la Orden del

${ }^{6}$ A.C. Za 1412-8 Legajo (C-1) doc. N. ${ }^{\circ}$ 7, Privilegio en el que Alfonso VII en 1139 donaba a La Iglesia de San Salvador de Zamora y a su obispo, Bernardo parte que tenía en la presa de Pinilla.

7 A. Represa, ob. cit, pág. 10, Señala como el tipo dominante de aglomeración es la puebla en torno a la Iglesia con un cierto aspecto de aldea, desligada de la ciudad en ocasiones por constituir un núcleo privilegiado.

8 A. Represa ... pág. 19. 
Hospital, que al parecer tenía en nuestra ciudad la casa central de la Bailia de Castilla $^{9}$.

El auge lo alcanza realmente en el siglo XIII Santa Lucia, puebla que parece haber sido el centro de asentamientos de judíos y comerciantes, lo que se corrobora porque en el año 1167, el obispo Esteban concede a las mercaderes de Zamora, que parecen estar representados por un tal Pedro Didaci, la facultad de construir una iglesia junto al puente nuevo, en las proximidades de la puerta de Ollas y Balborraz, esta iglesia va a ser la de San Julián del mercado. "Surgió asi un nuevo mercado al que de una parte abocaba el puente $y$ de otra Balborraz ${ }^{10}$. Lugar de asentamiento de artesanos, comerciantes, obradores Es incuestionable que la instalación del mercado en la puebla del Valle contribuyó a la densidad de la misma. Esta puebla de la que hemos hablado, una de las mas importantes de Zamo$\mathrm{ra}$, quedó englobada en el tercer recinto murado protegida por tanto de los peligros exteriores que en este momentos estaban representados por Portugal, recinto que en línea recta iba de Puerta Nueva, Santo Tomé, paralela al río, puerta de Ollas frente al puente nuevo y muy cercana a la puerta de San Simón. Las pueblas que hemos analizado se constituyen dentro de la ciudad por tanto protegidas por las murallas a excepción de las que se extienden hacia el río, zona artesanal por excelencia, cuya muralla natural sería el río. Ese amplio recinto amurallado tenía un total de catorce puertas, pues a las ocho, que ya he citado para el primer recinto, habria que añadir la puerta de Santa Ana, San Torcuato, San Miguel, San Pablo y Balborraz situada en el segundo recinto y la puerta de Ollas del Puente se abriría en el tercer recinto.

Murallas, puertas, ruas e Iglesias ¿Con estos datos podemos conocer la vida de la ciudad? Pues evidentemente no, por tanto esos espacios deben ser revividos y para eso nada mejor que adentrarnos en sus espacios. Una ciudad no sólo se caracteriza por las iglesias, pero es evidente que en Zamora contrastaban estas construcciones religiosas con las humildes casas que jalonaban las calles, para ellas una arquitectura modesta. Las casas parecen haber sido de madera, material peligroso por su propensión a incendiarse y a provocar por lo tanto graves problemas. Todavía en el siglo xilI en algunos lugares las casas cubrían sus tejados con paja, lo que también conlleva sus peligros, tal es el caso de Cuenca ${ }^{11}$. Normas acerca de cómo se debían hacer las casas y cubrir sus tejados las había, pero no siempre se cumplía. Quiero resaltar que las normas tienen un sentido, y es que lo que se levantaba, lo que se construía redundase en beneficio de las personas que habitaban la ciudad, el determinar que unas determinadas construcciones se hicieran de un material o que se cubrieran con tejas no tiene más que una lectura, hacer menos peligrosos los incendios Por tanto infringir las normas supone crear un riesgo para la seguridad de los vecinos, de otras casas.

\footnotetext{
9 A. Provincial de Zamora. Carpeta n. ${ }^{\circ} 1$, doc. N. ${ }^{\circ} 8$.

10 A.C. Za $1425-17$ (E-I) doc. n. 15.

11 Fuero de Cuenca, Ureña Smenjaud, Madrid 1935, capítulo II, artículo 43.
} 
Casas urbanas, por tanto, de madera, de tapial, de adobe para las gentes comunes. Las iglesias y las casas de los nobles, generalmente, se construían en piedra. Se suele mencionar de una manera general la anarquia de las construcciones medievales, lo que parece que también pudo darse en Zamora donde no había un respeto a las alturas de las casas, cada uno construye según le parece o quizá más acertado sería decir que se construye en función del espacio que se tiene, lo que será en buena medida el causante de una parte de esa anarquia.

Pero aun con esta anarquía en la construcción, lo que me interesa es el significado de la casa. La casa representa algo íntimo, personal, privado, seguro. La casa es el lugar privado por excelencia donde vive la familia, recinto privado de puertas adentro donde nadie ajeno puede entrar, salvo en casos muy concretos. $Y$ por eso nadie entra a la fuerza en una casa y si lo hace será acusado de "allanamiento de morada" ¿Allanamiento ? y ¿qué entienden las gentes medievales por allanamiento? Allanamiento es entrar en una casa sin permiso y con un objetivo, matar o herir. Eso es allanamiento. Todos se sienten protegidos en el hogar. La casa es seguridad frente al exterior. Íntimo y privado de puertas para adentro, pero por fuera, en el exterior, es decir, en lo que representa el edificio hacia la calle, eso es otra cosa, eso ya no es privado es parte de lo público. Desde este concepto de lo público todos están obligados a mantener las fachadas en condiciones para evitar que un edificio se venga a bajo y cause lesiones a los que están en sus cercanías, y esto es algo que compete a los vecinos. Bastará con que se advierta a los propietarios, a los inquilinos de las malas condiciones de un edificio para que desde ese instante, desde el momento en que se les ha apercibido por las autoridades, sepan que ellos son los únicos responsables de lo que allí ocurra. ¿Qué puede ocurrir? Puede derrumbarse una parte del muro sobre una casa y arruinarla , o una pared o adorno sobre alguien que pasa por la calle, esto conlleva graves penas ${ }^{12}$. Dejando volar la imaginación podremos ver casas de adobe para algunos de los moradores: las gentes corrientes. Casas sencillas, construidas con un material elaborado por los hombres y las mujeres, por toda la familia. Todos son conocedores del arte de mezclar el barro con el agua, conocedores de mezclar las pajas, del secado, de darle la forma casi perfecta de rectángulo. Se desparramaban las casas con anarquía por las rúas, otras se construian en la muralla, éstas eran las que levantaban aquellos que desafiaban las normas del concejo. Pero las casas en Zamora, en su mayoría, estaban construidas en madera, eran fácilmente destruidas, frágiles como la vida misma en la Edad Media ${ }^{13}$. Pero un hecho es real y no debe olvidarse: la casa se ofrecía, en el espacio inseguro de la ciudad, como el mejor refugio contra todos los peligros que acechaban, especialmente por la noche. Casas débilmente alumbradas con candelas, selladas las puertas y ventanas con cera, la gente en ellas se sabia a salvo y ése era el recinto de su

12 Ibídem, todos estos aspectos pueden verse en el capitulo VI y en los diferentes artículos del mismo donde además de hacerse referencia a las armas prohibidas dentro de la ciudad, se hace mención de todo lo que he comentado en el texto.

13 Véase mi estudio, Dejando hablar a la Edad Media. Especialmente los dos primeros capítulos. 
vida privada. No nos importa si esta vida era cómoda o no, importa el señalar que dentro de la casa se desenvolvía la vida privada por excelencia.

Tratemos de imaginar las viviendas a través de las representaciones que nos han llegado,de madera, de adobe, da igual, lo único real es la casa es el espacio conocido, seguro y querido. En la mayoría de las casas el suelo al que se accede desde el exterior no estaba enlosado sino que era de tierra pisada ${ }^{14}$. No resulta difícil imaginar como podía ser una casa en la Edad Media, en las que se pueden concebir varios espacios reducidos e incómodos. Podía existir una escalera que llevaría a la parte de arriba. Se carece de espacios amplios, siendo la cocina la parte principal de la casa. Se cierran al exterior con puertas de dos hojas, llevando las más sencillas travesaños claveteados para asegurar la tablazón vertical, otras aseguran las tablas con herrajes y ventanas. Generalmente había pocas ventanas, pues pensemos que cuanto más huecos tuvieran más frío se pasaba. ¿Habitaciones? Depende de la categoría de la familia. Escasas comodidades. En su interior, son pobres. Con pocas cosas. Puede haber en lo mejor de los casos dos pequeñas salas con unos camastros.

Se puede imaginar el interior de un casa del siglo XIII, una alcoba o posiblemente dos; en algunas casas de artesanos se añaden los talleres. No hay muchos muebles, la convivencia se hace alrededor del fuego, la misma olla de comida para todos los miembros que comparten en el mismo recipiente el alimento. Algunas de ellas tienen bodega y a veces letrinas ¿Casas seguras? En absoluto, paredes inclinadas que eran perforadas sin grandes problemas por los ladrones. Lógicamente estos problemas van disminuyendo a medida que se desarrolla más la ciudad y empiezan a contemplarse otros medios que hacen de las casas un medio más cómodo, algo más digno incluso en cuanto a su higiene.

La mayor parte de las casas que se van levantando en la ciudades son de carácter muy humilde pero hay también casas que son de la gente de solvencia, de los hombres «buenos», de los nobles, de los eclesiásticos. Éstas tienen más de una cámara y no son de madera ni de adobe, ni tienen el suelo de tierra pisada. En ellas es frecuente encontrar ciertas comodidades que son relevantes para el período, como por ejemplo la individualización de espacios dentro de la misma, por supuesto más evidente en el siglo Xv. Los testamentos dan bastantes datos acerca de los espacios internos de una casa, tal es el caso de García Peláez (1251) Cantor de la Catedral de Zamora, llevaba a cabo su testamento y en esa escritura se aprecia cómo su casa no se corresponde con las humilde moradas que he señalado más arriba. En su vivienda se contabilizaban varias mesas, escaños, redomas, arquetas y arcas de diferentes tamaños claveteadas de gran valor. García Peláez no era persona cualquiera ni por su cultura ni por su puesto ni por su riqueza, su dinero lo tenía invertido en préstamos, y esto le daba amplios beneficios

14 M. F. Ladero Quesada, Zamora en la época de los reyes católicos: Economia y Gobierno. Zamora,1991. Señala como todavía en el siglo xv como en muchas casas de la ciudad de Zamora cuando barrian sacaban al exterior, parte del suelo,sus pajas y estiércol, amontonándose en la calle. 
que le permitían vivir con plenas comodidades. En su hogar no habia carencias y esto se aprecia no tanto por el dinero ni por los muebles sino por la ropa confortable que menciona ${ }^{15}$. No se puede decir que tuviera una casa reducida por el contenido que dice tener en ella, en concreto en las salas más privadas donde se encuentran los lechos: tres cocedras con tres xumacos y tres façolos. Evidentemente aquí no hay pobreza, esa pobreza que haría señalar dentro de la casa un simple colchón de paja. Quizá los Xumacos son de piel. Tres lechos por lo menos claramente vestidos con toda su ropa de cama. Colchas que las cubren y buenas mantas. Su casa reúne las comodidades de los privilegiados y no de las gentes corrientes. En pocas casas se podría contabilizar tanta ropa de cama, vestidos, tapetes, muebles mesas, escaños y un número importante de cubas y de grano. No, no todas las casas en las ciudades son las mismas. Espacios privados, donde se vive la pobreza o la abundancia. En cualquier caso, espacios de lo privado que sólo pertenecen a las vidas de los que alli viven. ¿Que decir de los espacios públicos?

Pero alejémonos de los ámbitos privados que se ubican en el espacio público y vayamos directamente hacia los espacios abiertos, los que corresponden a todos los ciudadanos. Nada mejor que adentrarnos por las calles y las plazas medievales, lugares que no están vedados a nadie. Si nos damos cuenta el espacio abierto se corresponde con el público, que queda bajo el control directo y vigilancia de las autoridades locales, obligados a velar por la conservación del mismo o al menos mantenerlo lo más dignamente posible. En este espacio las calles y las plazas alojan los edificios que están destinados a las funciones públicas y que van incrementándose en la medida que la ciudad se va desarrollando, casa de las autoridades, cárceles, puertas fortificadas, torres, fuentes, incluso se consideran también espacios públicos las tiendas, los mesones, talleres artesanales, tabernas dentro del espacio de diversión y los edificios que prestan una labor asistencial como pueden ser los hospitales.

Las calles. Espacios de convivencia. A un lado y a otro se levantaban las casas de la gente. Calles estrechas, cortas, sinuosas, peligrosas. Esa estrechez de las calles hace difícil la convivencia, porque da la sensación de que en la ciudad la convivencia no era buena y es claro que un espacio estrecho aproxima demasiado a las gentes. Las calles eran espacio de convivencia diaria, donde se vivía y también se está en contacto con el miedo, con la violencia. Para un hombre acostumbrado a los espacios abiertos las rúas, los espacios que le ofrece la ciudad, quizá se le presentasen muy estrechos. Son los espacios abiertos y públicos destinados al tránsito y que se abren entre las construcciones que se van levantando bastante irregulares al compás de las calles y donde se destacarán unas vías principales de otras secundarias. Calles dificultosas por su estrechez, tari estrechas que se hace preciso regular el movimiento de carretas o de los transportes que llegan al mercado. En ellas sin ningún tipo de orden, se han ido levantando talleres, tiendas, y es indudable que sus dueños, cada uno de los que han instalado sus negocios o

$15 \mathrm{ACZ}$, leg.18, doc.12. Año 1251. 
levantado las casas, no ha tenido en cuenta más que sus propios intereses, con lo cual en ocasiones a las calles estrechas se les va robando espacio y luminosidad: La estrechez de algunas calles y callejas se agrava aún más porque muchas veces las casas se expansionan construyendo saledizos y balcones que roban espacio a la calle y otras veces porque se colocan, sobre todo en las casas de los artesanos, bancos, poyos, tableros y sillas que la hacen más angostas y de paso más difícil ${ }^{16}$.

Esto es un problema que irá creciendo en la medida que va progresando la ciudad y se va incrementando el número de construcciones, robando más espacio. Un espacio que no sólo será espacio físico sino ambiental, de tal manera que en el siglo $x v$ se puede imaginar en un bello monólogo lo que pensaría un campesino que ha conocido lo que es el espacio abierto, lo que es caminar en plena libertad sin problemas con sus animales, con su cesta y llegar al espacio cerrado de una ciudad. ¿Se sorprendería? Sí, y entonces pensando en voz alta quizá pudiera decir:

Et dime que maravilla ay en esto. Ca veemos que quando andamos por la calle algund embargo nos fazen los siervos que andan de una parte a otra mas no los matamos por esto. E las paredes de las casas con su altura embárganos la luz et las lonjas et los hedificios que se fasen par deporte et las casas hedificadas en el suelo de las cibdades embargan de nos andar por donde queremos pero no las derribamos para se mas libre el andar ${ }^{17}$.

Casas hacinadas en espacios muy estrechos, en medio de calles tortuosas y angostas que daban la sensación de congestión. Son lugares de convivencia donde la gente se encuentra, donde la gente trabaja y donde la gente establece toda clase de relaciones. En Zamora calles emblemáticas como el Carral Mayor, que si bien es calle estrecha, no era sinuosa, sino más bien recta, iba desde la Iglesia del Salvador, el primer tramo, hasta la puerta del mercadillo, que sería un primer sector para depués continuar hasta Puerta Nueva, paralela a esta vía fundamental, la rua del mercadillo, donde se dio en el siglo xII un mercado y quizá dio origen la calle de carniceros, Balborraz, la rua de los francos, la rua de San Andrés son espacios donde se producen los contactos de la vida cotidiana. En general las calles eran estrechas y así en ocasiones se verá, especialemnte en las normas del siglo XV como la estrechez de las misma hace que oficios como el de lo odreros y cabestreros, vendedores de sogas, se les prohibiese que colocaran su mercancía en las puertas de sus casas, simplemente porque esa mercancía expuesta provocaba numerosos problemas a las personas que se desplazaban por las calles. Espacios plenos de actividad y de gente durante el día y sólo por la noche quedan totalmente vacios a partir de una determinada hora. La calle tiene una gran importancia y, en general, solían estar muy descuidadas, lo que no quiere decir

${ }^{16}$ M. F. Ladero Quesada, La vivienda: espacio público y espacio privado en el paisaje urbano medieval, en, La vida cotidiana en la Edad Media, Instituto de Estudios Riojanos 1998 . En el recorrido que hace por los espacios de una ciudad medieval sigue dos modelos, por una parte el de César Álvarez y por otro el de José María Sánchez Benito. Se refiere en el caso del primer autor al estudio de la ciudad de León y en el segundo al de Cuenca.

17 Arch. Prov. de Zamora. Libro de las Lamentaciones, Carpeta 10, expediente 2. Siglo XIV. 
que las autoridades de la ciudad no intenten que las cosas sean de otra manera. Intentar que las casas mantuviesen un orden en las construcciones era casi imposible, evitar que no se destruyan las murallas levantando en ellas las casas de algunos ciudadanos era otra tarea casi imposible de conseguir. La prohibición existía, lo que no se puede comprobar es que se respetase. Lo mismo puede decirse acerca de la limpieza de las mismas. Normas había. Sabemos que aquellas calles que por su actividad eran más sucias se exigían una limpieza diaria y frecuente. Las noticias sobre la limpieza en Zamora no son excesivamente positivas y como ocurría en todas las ciudades la suciedad se amontonaba en los lugares que no se debía y además en esa basura podía aparecer toda clase de animales muertos y en putrefacción. La suciedad por las lluvias y los barrizales que se formaban era otra de las preocupaciones de las autoridades, pero la preocupación de llevar acabo un adecentamiento de las calles desborda a las autoridades del municipio y serán los particulares quienes llevarian a cabo estas iniciativas. En algunos casos hablan de empedrar las calles como necesidad para evitar el lodazal que se forma en ellas, éste es el caso de Salamanca a finales del siglo XV ${ }^{18}$. Estrechas y sucias. La calle es de todos y para todos, es el lugar donde se exhibe cualquier cosa es un lugar sucio, poco higiénico. En ella se percibía la riqueza de los habitantes por sus ropas y la miseria de los pobres por la suciedad.

Calles sin personalidad en un principio, pero a medida que las ciudades se van desarrollando la calle adquiere una mayor dimensión y los edificios y todo lo que compone el espacio público se va ornamentando, y se van cuidando más los elementos que atañen, por ejemplo a la higiene y la vigilancia de las mismas. La calle adquiere su personalidad ¿Qué significado tiene el aplicar el termino de personalidad a una calle? La calle adquiere su personalidad, no tanto por los edificios que aparecen en ella sino porque se van delimitando sus espacios, unos espacios que van señalando con precisión meridiana y clara los lugares que corresponden a los diferentes estamentos de la ciudad.

La parte más alta será la más protegida, la más segura dentro de la muralla, la cercana a la catedral que corresponde al primer recinto amurallado, es el dominio de las gentes de la iglesia, de los alcaldes, de los principales, rúa de los francos, notarios, damas, sus nombres indican ese espacio libre, noble. Va descendiendo y desbordándose la ciudad en la medida de su progreso y su desarrollo, ampliando sus primitivos límites, estableciendo a través de sus espacios que rebasan sus murallas una mayor diferenciación entre las gentes que la viven y que trabajan, carniceros, laneros en el segundo recinto. La diversidad de trabajos es un hecho y también que no todos ellos son dignos. La zona comercial, la más alejada de la muralla, dejará su huella en calles gremiales, zapateros, herreros, tejedores, curtidores, la mayor parte de estos lugares se ubican en la tercera ampliación.

Por tanto en el siglo XIII la calle empieza a conocerse por las actividades que en ella se realizan, es en este sentido en el que la calle adquiere su personalidad.

${ }^{18}$ Carmen Carlé, La sociedad Hispano Medieval: la ciudad. Barcelona 1985. 
Simplemente va recibiendo su nombre adecuado y determinante con el que indica a lo que se destina esa calle, qué actividad se desarrolla o qué personaje famoso vivió en ella. Antes de entrar en la calle de curtidores ya se conoce lo que allí se va a encontrar. Calles con personalidad como tenerías, carpilleros, herreros, zapatería son emblemáticas y dejan su huella. Son lugares concretos, únicos. Sus nombres definen, en este caso una actividad.

Van ensanchándose las calles dando lugar a las plazas, que constituyen también para los personas medievales elementos de convivencia y de reunión de suma importancia. Lugar poco discreto, en ella se está ante la mirada de todos como demuestran los textos literarios.

Hablar con mujer en plaza es cosa muy descubierta
y, a veces, mal perro atado está tras la puerta abierta;
es bueno disimular, echar alguna cubierta,
pues sólo en lugar seguro se puede hablar cosa cierta ${ }^{19}$

Las plazas no son de grandes dimensiones. Al menos en el caso de la ciudad de Zamora. Acaso más anchas que las calles, poco más, pero con qué terrible dificultad se adentran las carretas por algunas de ellas, apenas se puede descargar la leña, el carbón o la paja. Para estas mercancias hay que buscar lugares más amplios, nunca lo harán ni en Santa Lucía ni en San Juan de Zamora. Es una carga que abulta demasiado y no dejaría espacio para moverse con cierta holgura ${ }^{20}$. Por lo tanto esa ampliación a la que me refiero no parece haber afectado a todas las ciudades. Sin embargo si puede decirse que desde el siglo XIII algunas de estas plazas tienen personalidad propia porque tienen nombre, la de San Juan, la de Santa Lucía. Éstas son de pequeñas dimensiones, y frente a ellas, destacando por ser de mayor amplitud, tenemos la de Garci López y la de Santiago ${ }^{21}$.

Las plazas estaban destinadas a muchas y variadas actividades. En las castellanas se hacen pregones, anuncios judiciales, ejecuciones. Pero además de todo esto como espacio de convivencia la plaza es sobre todo el lugar de encuentro por excelencia, lugar de actos públicos, lugar de encuentro de las personas que cada noche tienen que hacer la ronda por la ciudad y vigilar , lugar en «donde se cuece todo", que con mucha razón Sánchez Benito define como el mentidero por excelencia de la ciudad.

Este dia en la plaça de la Picota, onde estaba mucha gente, los dichos dixieron... que por rason que agora muchos tales vesinos e moradores de la dicha cibdad que ende estavan en la dicha plaça se quexavan e les disian e fasian saber ${ }^{22}$.

${ }_{19}$ Arcipreste de Hita. Libro del buen amor, verso 656. (versión de María Brey Mariño) Madrid 1976.

${ }^{20}$ M. F. Ladero Quesada Zamora en l la época de los Reyes católicos, Zamora 1991. pág. 409 y ss.

21 lbidem.

22. J. María Sánchez Benito El espacio de Cuenca en el siglo xv, Cuenca 1997. Opina que no tenemos grandes plazas en nuestros espacios urbanos hasta el siglo xiv y xv. Nos remite al ejemplo de Cuen$\mathrm{ca}$, que se define con varios nombres, todos ellos muy significativos: Plaza de la Picota, está haciendo referencia a un espacio dedicado a la justicia; plaza de Santa María hace referencia a un espacio religioso quizá desde el punto de vista de las celebraciones, y por último, se la denomina del mercado. 


\section{LOS LUGARES DE ABASTECIMIENTO}

El lugar público por excelencia sería el mercado ubicado en el tercer ampliamiento de la ciudad. Lugar de abastecimiento de la ciudad y del territorio, lugar de concentración de muy diversas gentes de buen y mal vivir. El mercado debia ser un lugar donde la paz, donde la tranquilidad imperase, para lo cual se arbitran medidas de vigilancia que ejercían unos oficiales del mercado que procedían del gobierno de la ciudad. Todos los martes se procedía a fijar los precios de los productos que se iban a vender en él, los pesos eran del concejo, solían estar arrendados. En ello se pesaban las mercancías se confiaba en ellos, porque el peso efectuaba sin fraude. Allí acudían todos los pecheros que al contribuir, no deben pagar por su utilización ${ }^{23}$. Se situaban en lugares muy concretos y estratégicos de la ciudad, es decir, en la zona de más comercio: San Juan, Santa Lucía, San Leonardo y Santa María de la Horta.

Da la sensación de que los vigilantes se encontraban muchas veces con alteración de los precios, de las mercancias. Un buen ejemplo hace referencia a la venta de los animales, porque al parecer a veces se vendian en pésimas condiciones lo que sólo se podía apreciar después de dos días o varios, para evitar estos fraudes se determinó que los vendedores de estos animales debían entregarlos al comprador, que tendría ocho dias para observar si los animales están en buenas o malas condiciones. En caso de que no lo estuvieran, se tiene que devolver el importe que se pagó por ellos, tras la devolución de los mismos al fraudulento vendedor ${ }^{24}$.

Los contactos con la vida material se producen por tanto en toda esta zona comercial, en ella los lugares por excelencia son los de abastecimiento. En Santa Lucía se encontraban las tablas de las carnicerías más famosas de la ciudad también en San Juan, abastecidas de todo tipo de carne, al parecer los carniceros tenían que tener todo lo que la ciudad demandaba, incluido si se presentaba un imprevisto cómo puede ser la visita del rey o de algún personaje ilustre ${ }^{25}$. Había todo tipo de carnes vacuno, cerdo, cabrito, cordero, que no aparecen mezcladas, sino claramente diferenciadas.

23 Cual homne que postor se del conceyo, o muller del postor, cual cosas quesier pesar por los pesos del cunceyo, peseyo sen precio e sen toda. Remito al artículo 75 del fuero donde se aprecia que los que pagaban al concejo se benefician de algunos usos comunales como pueden ser los pesos. El termino "toda" precisamente hace referencia a precio o impuesto que pagaban otras personas que no eran vecinos de la ciudad

24 En el artículo 60 del fuero de Zamora se dice que Homne que vendir bues cómo vezino, téngalos $I X$ dias. E se buenos fueren de arada, téngalos, e en el tiempo de las mieses, pruébelo en el carro e enna trilla. E se non fueran bonos, tórnelos a los IX dias a so dueño, e so dueño tórnele su haber. $E$ se le non tornar los bues hasta IX dias, no le responda, e se hata IX dias le los tornaré e non le dan so haber, use elos bueyes e prinde por so haber. $E$ se $I X$ dias fueren e pasados, non ye responda.

25 Véase Manuel F. Ladero Quesada, ob. cit., pág. 397. Los datos están extraídos de la documentación que aporta, la mención de carniceros, con sus nombres, que citaré en el momento adecuado, me permiten elaborar todo lo que hace referencia a este grupo de personas que abastecen a la ciudad. 
Las carnes ofrecidas debian ser de primera calidad. Lo más peligroso se presentaba cuando se compraba la carne cocida, porque no ofrecia garantías, a veces aun con vigilancia se vendía carne procedente de animales enfermos. En este caso además de pagar una multa se retiraba la mercancia, con el producto que se retiraba se nutrían los lugares donde había enfermos o pobres.

Es de destacar que algunos carniceros fueron importantes en Zamora, dejaron sus nombres en la documentación: Pascual Domingo, Diego Martín, Pedro Beneitez. Casi todos ellos solía residir en las proximidades de estas tablas, en San Julián del mercado. Todos ellos cumplen la misión de abastecer la ciudad de alimento, a las tenerias de pieles, a los candeleros, de sebo, y también aportan los toros para las fiestas. Algunos se codeaban con lo más selecto de la población y especialmente con los grandes cargos de la catedral. Se puede apreciar en la documentación como algunos canónigos debian de hacer negocios con ellos prestándoles dinero, a cambio de lo cual los carniceros les fiaban las mercancías ${ }^{26}$. Los carniceros a medida que avanzan las normas que se dan para la ciudad se ven sometidos a ellas y deben tener mucho cuidado en la forma de vender, no se debe vender a ojo sino a peso y se pone limitaciones a las compras que ellos hacian del género ${ }^{27}$. Los carniceros abastecían de carne a los que venían de fuera, de las aldeas y por supuesto lo que estos se llevaban debía ser vendido al mismo precio que se vendia en el mercado de la ciudad. Los pesos como ya he señalado eran de vital importanbcia para poder vigilar todos estos aspectos y así en las cercanías de dichas tablas estaban los pesos de la Plaza de San Juan y el otro en Santa Lucia.

En la misma zona estaban las tablas de las pescaderías, da la sensación de que todas las que vendian en el mercado eran mujeres. Sabemos que no todas podían exponer su mercancía en las mesas, por lo tanto la mostrarán en el suelo y donde las autoridades del mercado dijesen. Sujetos estos vendedores a las normas que se van imponiendo, asi por ejemplo el pescado debería estar expuesto en las mesas sin agua, y no podia tenerlos en las artesas, y debían pesarlo en balanzas horadadas. Al igual que los carniceros estas pescaderas vendían su género en San Juan y en Santa Lucía. Ni que decir tiene que toda la mercancía era vigilada y no se podia vender a cualquier hora sino a las ocho horas de la mañana, que debia marcar el reloj de la plaza de San Juan, esto desde el primer día de octubre hasta finales de febrero, corriendo el riesgo de perder la mercancía si no se respetaban estas normativas.

También entre estos pescaderos abastecedores había gente importante. Suele figurar un tal Ferrán, residente en Balborraz que al menos en algunas ocasiones había abastecido a los reyes con sus mercancías ${ }^{28}$.

${ }^{26}$ Este es el caso del arcediano Pedro Anayz (Yañez) ,el cual a la hora de hacer el testamento incluye cómo deudor a Pedro Beneitez, aunque reconoce que él también le debe un cordero.. .Ver A. C. Za. Legajo 18, documento, n. ${ }^{\circ} 20$, Año 1294.

${ }_{27}$ Manuel Fernando ladero Quesada, ob. cit., pág. 398.

${ }^{26}$ Remito a Mercedes Gaibrois al apéndice documental sobre las cuentas del reino de Sancho IV, en esta obra se aprecia cómo en el año 1294 se ordena que se pague a Ferrán de Zamora pescadero CCXXX mr. CXI. 
Se puede decir por lo revisado que habia variedad de alimentos, que la ciudad estaba bien abastecida. En Santa Lucía se ubicaban también las panaderas; al parecer la venta sólo la podían hacer en el mercado las seis mujeres primeras que llegaran al lugar, de todas las maneras las mujeres que tenían hornos en sus casas, amasaban el pan y lo vendian por las calles sin embargo no era frecuente tener hornos en las casas, hemos de pensar que los hornos dentro de las casas eran un fuerte peligro para unas construcciones que en su mayor parte eran de madera, lo más utilizado era el horno comunal que podían emplear los que pechaban con el concejo, sin pagar por utilizarlo. Éste es un lugar que parece reservado única y exclusivamente a las mujeres. Alli iban a cocer el pan. El horno es espacioso y está provisto de abundante leña, es un espacio de convivencia femenina, allí se habla de todo lo referente a la vida cotidiana y también, lugar donde las riñas entre ellas son más frecuentes.

El mercado lugar de abastecimiento, donde se venden cosas necesarias para la vida cotidiana ¿acaso no son importantes las candelas? Interesante saber el proceso. Se debía someter los tejidos de los animales a un proceso de cocción que permite separar el sebo, había calderas, pailas y arrobas de sebo. Una vez que se habia cocido y se separaba el sebo, se labraba esa masa y se colocaba en los moldes. Los mejores candeleros eran los que labraban de una misma pieza es decir, toda por igual. Las candelas y cirios si daban bastante luz se debía a que los pabilos eran realizados en lino. También se tiene el nombre de uno de los cereros más importantes del siglo XIII en Zamora, Salvador ${ }^{29}$.

Por lo aportado por Manuel F. Ladero Quesada, también a los cereros había que vigilarlos porque podian llevar a cabo la mezcla de otros materiales con la cera ${ }^{30}$, candelas, cirios, velas, constituyen el material elaborado por estos cereros. Del estudio de la actividad del mercado, de las normas que se imponen en el siglo $x v$ podemos conocer los alimentos que consumían los vecinos de la ciudad. Harina, garbanzos, pan vino, carnes de diversas clases, cabrito, carneros, vaca, asaduras, riñones, tripas, truchas, pescados diversos, frutas que da la sensación que procedían del territorio, productos cocinados.

29 Para llevar a cabo esta interpretación he seguido tres tipos de información. El nombre del cerero no es una mera elucubración sino que en las cuentas del rey don Sancho Volumen Ill de Mercedes de Gaibrois de Ballesteros encontré la mención de un Salvador de Zamora, cerecero al que se pagaba por haber proporcionado xxx arrobas de cera $\mid 1 \mathrm{mil}$ CC $\mathrm{mr}$. Apéndice documental $\mathrm{CXI}$, nombre que me da pie para indicar este negocio de la candelería en general. A través del estudio de Ricardo Córdoba de la Llave, La industria medieval en Córdoba, Co, 1980 supe que las candelas se hacían de cera que se obtenía de las abejas o del sebo. Es evidente que en Zamora esto se producia a través del sebo que aportaban los carniceros a los cereros, pero también se menciona la cera lo que quedó corroborado con la lectura atenta de las ordenanzas de los Fieles de las carnes que transcribe Manuel M. Ladero Quesada en la ob. cit., pág. 403. Es importante señalar que en el monasterio de Santa María de las Dueñas, las monjas empleaban tablillas de cera para comunicarse con los dominicos, al menos esto sucedia en 1279 como se deduce de la documentación manejada. Remito a mi estudio. «El monasterio de Santa María de las Dueñas de Zamora ¿Religiosas o beguinas? El proceso de 1279", en "Historia. Instituciones. Documentos" 20, págs. $85-103$.

${ }_{30}$ Manuel Fernando Ladero Quesada La ciudad de zamora en la época de los Reyes Católicos: economia y gobierno, pág- 403, Zamora 1991. 


\section{LAS ZONAS GREMIALES}

No completaría el panorama de la ciudad de Zamora sin hacer mención de la zona artesanal. El eje fundamental la calle Balborraz, una de las calles más comercial y a la vez más sucia de todas, en ella y en sus aledaños se encuentran calles gremiales. Calle de los herreros. La actividad de los herreros en una ciudad medieval es importante porque de sus manos salian multitud de utensilios necesarios para la vida cotidiana como las rejas de arar, los hierros con los que se marcan los ganados, los candeleros, sartenes los grandes picos, hachas, martillos, barras y clavos. Todos estos objetos mencionados se emplean en diferentes usos. Asi se sabe que los carpinteros empleaban los picos y barras para apagar los incendios, de aquellos con toda seguridad salian las llaves de las grandes puertas de madera de la ciudad, las pesadas cerraduras, los cerrojos. Se recomienda que los clavos se compren por peso ${ }^{31}$.

Así como los herreros se sitúaban a la Izquierda de Balborraz, descendiendo por esta nos encontramos con las calles que alojaron a los que trabajaban el oro y la plata, gentes muy especializadas que llevaban a cabo verdaderas obras de arte, Suponemos que trabajaban para los ricos nobles, pero lo que es evidente, porque así lo refleja la documentación, parte del tesoro de la catedral podía salir de estos talleres, no solamente realizado por encargo sino que en estos talleres se reparaba los objetos que estaban necesitados de dicha reparación. Hay que pensar que la catedral era la Iglesia que con más boato y más lujo celebraba sus actos litúrgicos y esto debia reflejarse en todos los utensilios que se utilizaban para rendir culto a Dios.

Las cruces podían ser de leño, que de hecho lo eran, pero esto sería poco representativo para una Iglesia que representaba la cabeza de todas las demás, y en virtud de esto se revestían las mismas con laminas de oro, de plata e incluso a veces se le incrustaban piedras preciosas. Las vinajeras, los cálices, los candelabros, eran de plata. Es muy posible que visitando un taller de estos artesanos se pediesen ver algunas de estas preciosas joyas que la catedral tenía ${ }^{32}$ obras primorosas que, una vez reparadas, se muestran con todo el esplendor en los cultos y liturgias catedralicias. Los doradores o plateros trabajaban en sus grandes bancos donde

${ }^{31}$ Este comentario lo hago partiendo de las Ordenanzas que publica Manuel F. Ladero Quesada, en ob. cit., pág. 405. Por quantos los ferreros que fazen clabazon fazen en ella muchos engaños por la vender por quantia fasta aquj la an vendido mandamos de aqui adelante ninguno, non sea osado de vender clavazon mayor ni menor, ni por cientos ni por doçenas... e venda por peso. He creído conveniente introducir este texto porque creo que da una visión muy significativa de la picaresca de los artesanos y sus ventas y al mismo tiempo cómo en cierta manera la sociedad intenta ser organizada por el concejo.

32 En este aspecto los datos que aporto aquí sobre el tesoro de la Catedral están extraídos del Tumbo Negro de la Catedral de Zamora en el folio $154 \mathrm{r}$. En este inventario se aprecia cómo se citan algunas piezas que se dicen que están siendo reparadas y otras que ya lo han sido. Se nombran cálices de plata al igual que cruces que aunque son de madera se han recubierto con estos metales e incluso aparecen algunas de martil. Me parece lógico, que si la toponimia deja unos nombres cómo son calle del oro y de la plata y se habla de piezas reparadas, pensar e intuir que es en estos lugares donde se producian los aspectos que vengo señalando. 
colocaban la obra que querian enriquecer con las láminas del metal precioso. El dorador se sentaba sobre una banqueta y hacía su trabajo de recubrimiento de piezas con los metales que trabajaba o bien llevaba a cabo un cincelado sobre una pieza del calvario, con el cincel está resaltando las partes que quiere que sobresalgan. Necesita dos utensilios: el cincel y el martillo. Era un trabajo fino y de calidad. Es muy posible que además de obras religiosas, salieran algunas espléndidas destinadas a los grandes hombres de Zamora. Debemos recordar que los mas sobresalientes caballeros se hacen labrar las sillas de montar, y las vainas donde guardan sus espadas, y lógicamente se hacen decorar sus trajes con las piedras preciosas que quizá proporcionaban estos plateros.

Si seguimos descendiendo por esta calle y nos acercarnos a la Iglesia de la Horta, nos encontramos con lugares emblemáticos como. caldereros, alfamareros, carpilleros y el Zumacal, es decir zona artesanal por excelencia. de Zamora. Todos estos oficios son de importancia; los caldereros trabajan sobre el metal, no fino, pero de ellos proceden los grandes calderos que se emplean para diversos fines en la industria textil, una industria que dio cierta fama a Zamora. Materiales empleados el bronce y el estaño. El metal es golpeado con fuerza pues se trata de que la parte más gruesa quede en el fondo y las más finas quedasen en las partes laterales de las calderas, estas llevaban unas asas, o bien orejones ${ }^{33}$. Los alfamareros, hacedores de tapetes o alfombras, carpilleros, escardadores, nombres que reviven en la actualidad las labores medievales, porque se entraba en otra zona diferente donde se trabajaba con dos materias primas; la lana y la que procede del mundo vegetal. En el caso de la lana, los laneros de San Antolín aportaban a los peinadores y cardadores la materia prima. Estos laneros tenían su ámbito concreto, lo que hoy se conoce como calle de laneros. Los carpilleros y cardadores definen a los que limpiaban y abatanaban la materia que les llegaba para prepararla y trabajarla actividades que nos llevan a mencionar a los tejedores, los batanes, el paño. Para este trabajo se necesitan los batanes, donde en una enorme pila se sumergían los paños golpeados con grandes mazos de madera movidos por la fuerza del agua.

Debemos imaginar que en este lugar el trabajo es múltiple. No sólo se lava de todas las impurezas a los paños, sino que se lleva a cabo el enfurtido al golpearlo para darle textura, y alli está la pieza básica, de grandes dimensiones, que seguramente aportaban los carpinteros que sería: el gran bastidor de madera donde se colgaban los paños y se estiraban. El tundidor requiere que el paño que se le entregue esté bien terminado, bien igualado.

Pero la novedad más grande es la fama de algunos paños, reconocidos en todo el reino y que concretamente se hacía en Zamora. El rendimiento de los molinos treparios, la mayor parte de las veces en manos de componentes del cabildo,

${ }^{3}$ Aqui me he permitido utilizar una de las acepciones de asas, basándome en el nombre que hoy se da a la calle de orejones intuyendo que tal nombre le pudo venir de esta actividad que se produjo en la ciudad de Zamora. 
señalan la importancia de estas actividades ${ }^{34}$. Todas estas actividades se encuentran en las proximidades del río Duero, porque esta industria requiere una gran cantidad de agua.

Ese reconocimiento de los paños daría lugar a que en la ciudad existieran numerosos especialistas que tendrian que ver con esta actividad, cómo son por ejemplo los caldereros y los olleros ${ }^{35}$. Los caldereros hacian los calderos, donde se llevaba a cabo el teñido de los paños. El paño típico de Zamora era el "cárdeno", color que tiraba a amoratado. Para obtener este color u otro cualquiera se necesitaba contar con gente cualificada, porque es fundamental saber mezclar bien las tintas, y esto lo hacen los tintoreros. El colorante se hace con las hojas verdes pastel, y con ellas se inicia el teñido de los paños, se les sumergía en esa mezcla y de así se obtiene el color cárdeno. Los paños prietos de Zamora son los negros a los que se les da un tinte azul. En las proximidades de las tenerías se encontraba un terreno de arbustos de zumaque que a veces, no todas, se emplea en el teñido de los paños, digo a veces porque el zumaque tiene otro destino diferente. El proceso del tinte era muy complicado. Los paños debían ser lavados una y otra vez para que carezcan de impurezas. Los que más trabajo daban eran precisamente los negros, porque antes de ser teñidos habia que lavarlos muy especialmente en agua muy caliente para que no quede ni resto de jabón. Los paños se sumergen en esas tinas con los colorantes y se agitan con las manos y no con ningún instrumento de madera que pueda dañarles. Son especialistas que deben conocer qué sustancias deben darle a la lana para proceder a la fijación de los colorantes esto es lo que se llama "enjebar", que era preparar, tratar el paño con substancias como alumbre o rasura para que se pudiera fijar bien el color. Para estas labores parece que las tinas de barro eran las mejores junto con las calderas de bronce, pero cómo lugar de fermentación la mejor, la de barro. La mayor parte de las veces la importancia del paño se mide por el color. En Zamora el cárdeno fue el típico, pero también los prietos, granas y verdes.

34 A.C. Za. Legajo 18, n. ${ }^{\circ}$ 5. año 1242. Me baso en este comentario en la documentación donde se aprecia cómo el canónigo Parente tenía una parte en los molinos traparios. Esta actividad de nuestra ciudad lo demostró Paulino Iradiel Evolución de la industria textil castellana en los siglos XIII-XVI. Sa. 1974. El canónigo Juan Domínguez, tenía varias cámaras amuebladas con varios lechos. Y esto es importante porque el mueble más importante de toda la casa es el lecho, bueno pues el tenia tres por lo menos. Los colchones cubiertos de estopa, lino y lana. Todos ellos ser cubrian con cobertores que flevaban dibujos de manzanas, Los cobertores estaban forrados de pieles de raposas y de conejos, capas, sobrepelliz. estos datos me parecen importantes porque indican un poco la actividad en la que se movía la ciudad. Por otra parte señalar que los eclesiásticos eran bastante sensibles a lo que acabo de señalar, En el año 1274 las monjas de las Dueñas vendían al chantre de la catedral Don Juan unos molinos en la "zuda" que estaba cerca de tejares. El molino se denominaba Esquerdo, y la azuda en los pisones, todo en un entorno significativo ya que alli estaban las aceñas, teiares el molino Dornajo y no lejos de un lugar denominado "capilla". Ver. A.C. Za. Legajo 13, documento n. ${ }^{\circ} 68$. Año 1274. En el Tumbo Negro, folio 97, se alude a los "tanariis veteris pontis" en el año 1207, lo que Amando Represa pone en relación con la iglesia de San Salvador de los Curtidores de 1267, en Génesis y Evolución urbana, ob. cit., pág. 17.

${ }_{35}$ Quisiera hacer refernecia con respecto a los olleros, hay que señalar otra puebla que es la Vega, en el año 1279 doña Sancha donaba al cabildo unas casas, importa señalar los linderos que hace de las mismas "la cal que vay de sanxta María de la Vega a sancta Marina del barrio de olleros", dato importante porque nos ubica a unos de los oficios más importantes que tienen que ver con la industria. 
Por lo tanto en este proceso se da la combinación de tres grupos artesanales. Por una parte los que trabajan la lana y llevan a cabo la transformación en paño. Los tintoreros que les dan el color y los caldereros y olleros que aportan las calderas y las tinas para la mezcla de tintes. La tintura de los paños absorbe a una gran cantidad de gentes. En Zamora personas de un gran prestigio social guardaban en sus casas piezas enteras de paño, especialmente los obispos y canónigos, algunos de los cuales tenían su parte en los batanes dedicados a los paños. No sólo se sabe que guardaban paños sino telas lujosas porque en sus testamentos así lo dejaron escrito. Parece que es frecuente encontrar, en ellos, profusión de ricas telas de los más variados colores ${ }^{36}$.

He señalado otra materia prima el lino con el que se llevaba a cabo otra serie de tejidos. En Zamora mezcla de lino y algodón dio lugar al fustán, con el que se confeccionan una serie de prendas por los alfayates, algunos de los cuales se mencionan en la documentación. De los tejidos de lino salen algunas de las más delicadas prendas femeninas, cómo las tocas, cintas, velos para la cara, etc. También las iglesias se nutren con albas, estolas, túnicas, sobrepellices, que se emplean con gran profusión en las mismas. Ellos creaban las prendas sobre las telas ya elaboradas bien fueran de lana, de lienzo o de seda. Los alfayates conocían en el arte de cortar y de coser, son creadores de prendas nuevas o bien arregladores de otras que necesitan ser cambiadas de aspecto ${ }^{37}$. De sus manos salían jubones, sayas, faldas, garnachas, saraberas ${ }^{38}$. En San Leonardo, Juan Alfonso fue uno de los conocidos alfayates de la ciudad.

Dentro de la industria pañera destacaremos el terlliz tejido que se hace con tres lizas y que formaban cuadros o rayas Los alfayates realizaban garnachas con mangas de Blao $^{39}$, paños que quizá llegaban a través de unos ricos comerciantes cómo los Yañez. o los Fisaque, y también capas de Pres, que se refiere tanto a un tipo de paño especial cómo al que es azul.

Las tenerías, cercanas al río Duero, no lejos de Santa Lucía. adonde llegaban las pieles que aportaban los carniceros. Asociados a estas tenerías aparecen

${ }^{36}$ Al hacer este comentario estoy recordando cómo algunos canónigos cómo el maestro Gómez y Pelayo emplearon sus telas para hacer dalmáticas, hábitos, en este caso de color blanco. He encontrado también cómo en los testamentos revisados, a veces se reseñan con precisión paños de gran calidad que se guardaban en memoria de quienes fueron en otros tiempos sus dueños. Otras veces se dice cómo de un tela se hizo una determinada prenda. No se dejan de señalar bellisimas vestimentas de púrpura, y de variados colores.

${ }_{37}$ Basta con revisar el testamento de Gonzalo Gómez de Isla para encontrar con el dato al que me vengo refiriendo. En su testamento deja claramente establecido que de una capa de seda que se le dio mando hacer una vestimenta al alfayate Juan Altonso, que en el momento en el que el hace su testamento obra todavia en poder del sastre. Ejemplos cómo éste hay múltiples. Véase A.C. Za leg. 15, doCumento.$^{\circ} 27$. Año 1385.

${ }_{38}$ Todos estos trajes y prendas aparecen en la documentación que he manejado, especialmente en los testamentos. Con respecto a las saraberas, se hace mención en el monasterio de las Dueñas de Zamora. Esta prenda se refiere a unos vestidos flojos y llenos de pliegues, al menos, en Las etimologias de San Isidoro XIX, 23.

${ }_{39}$ Véase Charles Verlindem ,El comercio de los paños flamencos y brabanzones en España durante los siglos XIII y XIV. 1952; Gual Camarena Sánchez, M. Para un Mapa de la industria textil hispana en la Edad Media. 
otras tantas actividades, asi el curtidor que debía dejar la piel libre de todo resto de carne, eso es curtirla. Trabajo que se consideraba de alta especialización, no lejos de las tenería el zumacal, el zumaque era fundamental para el curtido de las pieles. Lo importante es destacar que en función del trabajo sobre la piel concurren varios oficios, personas conocedoras no sólo de la materia que tenían entre manos sino de las labores que debian darle en cada momento, así que al lado de los curtidores están los zurradores, golpeadores de las pieles, pellejeros, que como su nombre indica aportan las pieles y olleros. Generalmente casi todos ellos se situaban en la proximidad al rio, lo que no era una casualidad sino necesidad, porque eran tareas que necesitaban mucha agua. Pensemos que lo primero que deben hacer, cuando las pieles llegabann a las tenerías, era sumergirlas en agua limpia, y en ella se dejaba para que la piel se ablandase. El remojo se hacía en las grandes tinas con el pelambre, que contiene agua con cal, donde se las sumerge sólo después de haber estado remojadas y secas. La piel en el recipiente de la pelambre pierde las últimas impurezas. Siguen después una serie de labores que tienen cómo objetivo dejarla en condiciones para poderla curtir lo que sólo es posible si la tarea se realiza sobre una superficie completamente limpia. El curtido, se realiza con el zumaque. Habia varios elementos fundamentales, la pila de barro grande donde se apelambran, las tinajas de barro donde se dejaban fermentar las pieles y las calderas donde se calentaba el agua. ¿Podía tener alguna relación la calle de la manteca con estas actividades? ${ }^{40}$. De las pieles, aportadas por lo pelleteros, los zapateros, que se ubicaban cercarnos a Santa Lucía, (zapateria) hacían el calzado. De la piel se hacian las zamarras, los odres para contener el vino, los cintos con los que se ataban los jubones, las sillas para montar que llevaban los caballeros en sus caballos. También aportaban estos peleteros las pieles con las que se forraban algunas prendas, cómo las que llevaban algunas capas o algunas garnachas. Los peleteros, los trabajadores de las pieles, son un mundo aparte y dan la sensación de haber estado bastante unidos. Tenían sus propias cofradias y todos eran muy conocidos ${ }^{41}$. En estas cofradías se protegían durante la vida, en la muerte sus familias eran respaldadas y también si algunos se hallaban en una mala situación sabian que la cofradía les prestaria su ayuda, es muy posible que estos fueran de todos los artesanos los de mayor relevancia y los que constituían el gremio más importante de la ciudad.

Espacios materiales de la vida medieval en Zamora, donde cada Iglesia, cada calle son los testigos mudos de una sociedad que convivió a diario con las construcciones que hoy tenemos y con las calles por donde hoy deambulamos.

40 No tengo ningún dato concreto de esta interpretación que hago, sin embargo creo que no sería descabellado pensar que el nombre pudiera venir de la venta de la manteca para éstos y otros fines.

41 A.C. Za. Legajo 16, documento $n .{ }^{\circ} 46$, Año 1337. Estamos ante un acuerdo que llevan a cabo los representantes de los peleteros zamoranos con el párroco de San Julian del mercado, los nombres que aparecen son: Pedro y Juan Fernández este último procurador de la cofradia de Santa Maria y de San Julian, Pedro de la Parra, Alfonso Yáñez de Landrian, Martín Diéguez. 